Estudios Geográficos Vol. LXXIV, 274, pp. 341-356

Enero-junio 2013

ISSN: 0014-1496

eISSN: 1988-8546

doi: 10.3989/estgeogr.201313

\title{
Una visión territorial del conflicto armado en Colombia: la Unión Europea y el Laboratorio de Paz del Magdalena Medio, como propuesta alternativa
}

El pasado mes de octubre, el Gobierno colombiano dio apertura oficial al proceso de diálogo con la guerrilla de las Fuerzas Armadas Revolucionarias de Colombia (FARC). Este nuevo esfuerzo de paz invita a repasar las iniciativas que se emprendieron a comienzos de siglo para solucionar este conflicto armado. En dichos antecedentes, pretendemos destacar el apoyo realizado por Estados Unidos y la Unión Europea que concedieron especial importancia a la dimensión territorial de la confrontación. A continuación expondremos dichas estrategias, las circunstancias que las inspiraron y sus principales diferencias. Resaltamos asimismo, la pertinencia del enfoque europeo, al hacerse eco de las propuestas populares que plantean una alternativa novedosa para enfrentar la violencia. Dicho marco permite hacer una breve presentación de lo que fue la experiencia del primer Laboratorio de Paz en la región del Magdalena Medio.

Comencemos por describir el problema colombiano como un enfrentamiento armado, en el que además del Estado, concurren distintos grupos subestatales: las guerrillas que, por una parte, luchan contra éste por alcanzar el centro del poder político; y por otra, agrupaciones, hasta hace poco denominadas autodefensas, que encarnaron la reacción contra-insurgente, así como la protección de ciertos sectores ante la incapacidad estatal para brindar seguridad $^{1}$. Dicha disputa se ha desarrollado a lo largo de más de cuarenta años, tiempo en el que sus actores, motivaciones y características han cambiado gradualmente. Una de las etapas más significativas de esta realidad, se produjo a principios del siglo XXI, cuando el país se situó en el foco de la atención mun-

\footnotetext{
${ }^{1}$ Durante el segundo mandato del presidente Álvaro Uribe Vélez (2006-2010), estos grupos de autodefensa participaron en un amplio proceso de desmovilización. Sin embargo, la desactivación definitiva de este fenómeno es cuestionada, en tanto que varios de sus miembros han vuelto a las armas con la denominación de «águilas negras» o bandas criminales conocidas como «bacrim».
} 
dial por cuenta de la agudización del conflicto interno, las crecientes vinculaciones del mismo con la agenda global y la desesperada petición del país a la sociedad internacional para encontrar su solución².

Como respuesta a dicho llamamiento, los Estados Unidos y la Unión Europea formularon respectivas aportaciones, enfocadas en dos prioridades: frenar el despliegue del conflicto sobre el terreno y hacer efectiva la presencia del Estado en toda la geografía nacional. Sin embargo, sus propuestas fueron divergentes en sus planteamientos e instrumentos.

\section{EL DINAMISMO TERRITORIAL DEL CONFLICTO ARMADO: EL CASO COLOMBIANO}

Uno de los rasgos más significativos del conflicto colombiano es su dinamismo en el ámbito regional, tendencia que refleja la importancia estratégica que poseen los territorios en el desarrollo de las confrontaciones. En su estudio sobre esta cuestión, González incide en los aspectos comunitarios del territorio, advirtiendo que éste último no se reduce a la delimitación física de una unidad administrativa; sino que es un espacio que, además de sus cualidades geográficas, se transforma de acuerdo con las dinámicas sociales que le acontecen. Así, citando a Schnell, esta autora identifica tres dimensiones sobre los que descansa una circunscripción: i) la dimensión física, referida a la presencia de un grupo de población, con los mecanismos estructurales que representan su carácter y necesidades; ii) la dimensión social, que comprende la mutua interacción de sus habitantes, las relaciones de poder en la Comunidad, junto con los acuerdos y modelos que éstos establecen para el control y el uso del territorio; y iii) la dimensión de percepción y de comunicación que contempla la afinidad de los miembros de la Comunidad hacia el territorio, expresados en su sentido de identidad y de pertenencia ${ }^{3}$.

Como explica González, cada uno de estos pilares es alterado con la presencia de los grupos armados en las localidades, al irrumpir en las relaciones sociales y de poder entre los ciudadanos, con el propósito de establecer su base social (o diluir la del contrincante), y desde la misma, construir una infraestructura amplia con la cual realizar sus actividades ilegales ${ }^{4}$. Ante semejante potencial, el

\footnotetext{
${ }^{2}$ Ramírez, S. (2004): Intervención en conflictos internos: el caso colombiano (1994-2003). Bogotá, Universidad Nacional de Colombia.

${ }^{3}$ Schnell, I. (2001): «Transformation in Territorieal Concepts: from nation building to Concessions». Geojournal, 53/3.

4 Esta autora reseña el análisis de Blair, sobre el uso del territorio desde la perspectiva de la guerra: "[...] el territorio no sólo es el portador de enormes recursos económicos, un espacio 
control local se convierte en un objetivo estratégico para los combatientes, que obtienen a través de acciones ejemplarizantes de horror y miedo sobre la población $^{5}$. Esta virulenta filtración de la violencia se arraiga y se reproduce a partir de ciertas condiciones en los territorios. Unas relacionadas con sus ventajas políticas, tácticas o económicas que atraen a los aparatos armados; y otras, concernientes a la propia dinámica regional; es decir, la propensión de los pobladores a aceptar ciertos servicios brindados por los beligerantes en suplantación del Estado. Este comportamiento se generaliza ante la ausencia o ineficacia de las instituciones públicas ${ }^{6}$ y/o en el contexto de una profunda polarización social ${ }^{7}$.

topográficamente apto para su desarrollo, o una zona propicia al establecimiento de corredores estratégicos para la misma". Sino que supone el control y usufructo de todo lo que el territorio abarca, como la cultura, las relaciones de poder y los modos de vida de la población. Blair, E. (2006): “¿Nuevas Guerras? ¿Nuevos Espacios para la Guerra? o ¿Nuevas Especialidades?”, en D. Herrera y E. Piazzini (eds.): (Des) territorialidades y (no) lugares: procesos de configuración y transformación social del espacio. Antioquía (Colombia), La Carreta Social.

${ }^{5}$ A estos efectos, resulta ilustrativa la reflexión del PNUD sobre la dinámica local de la violencia en Colombia: «En vez de destruir al ejército enemigo, se trata "por ahora" de ir haciéndolo salir de las zonas que ocupa; y el mejor método para lograrlo es "quitar el agua al pez". Esto es, cortar sus nexos locales, dar muerte a sus enemigos reales o presuntos, atemorizar tanto a los vecinos que el enemigo no pueda retornar. Vistas así las cosas, se descubre que la crisis humanitaria no resulta de la confrontación militar sino, paradójicamente, de la falta de confrontación militar». Programa de las Naciones Unidas para el Desarrollo (PNUD) (2003): El conflicto, callejón con salida. Informe Nacional de Desarrollo Humano para Colombia. Bogotá-Colombia, p. 91. Disponible en: http://www.pnud.org.co/areas_documentos.shtml?x=1032\&cmd [82] =c-1-02002\&cmd[85]=c-1-02002\&conds[0] [category.......1] =02002\&als[VAREA__] = 02002. (Fecha de consulta: 15/07/2010).

${ }^{6}$ En su Informe Nacional de Desarrollo Humano, el PNUD apunta «[...] la presencia de un grupo armado suele beneficiar a muchos o a algunos habitantes en la zona. [...] Es común que guerrillas o paramilitares ofrezcan ciertos servicios a los lugareños, denominados "bienes colectivos locales". Estos se asemejan a los "bienes públicos" que compete al Estado proveer, aunque a diferencia de éstos, no pretenden cobertura universal ni se brindan sobre bases impersonales. El servicio de protección se presta frente a las agresiones del otro grupo armado, aunque así termine por erosionarse la seguridad de toda la colectividad. Y en cuanto a la justicia, a diferencia del servicio oficial, ésta es expedita y eficaz. Opera en tres áreas principales: delitos y contravenciones, conflictos familiares y civiles y conductas consideradas como desviadas, por ejemplo las minifaldas en las jóvenes». Programa de las Naciones Unidas para el Desarrollo (PNUD) (2003): El conflicto, callejón con salida..., pp. 67 y 68.

${ }^{7}$ Siguiendo a Mauricio Uribe, a lo largo de la historia colombiana, las armas han hecho presencia en el conflicto social y laboral de dos maneras: la represión estatal a las demandas de los trabajadores o ciudadanos afectados y por la infiltración de los actores armados en las organizaciones sociales y sindicales. Uribe López, M. (2006): «La colonización armada de los conflictos laborales». Boletín Hechos del Callejón, 11/enero, pp. 9-11. 
De acuerdo con la lógica mencionada, es posible rastrear la geografía del conflicto colombiano en distintas fases: las guerrillas nacieron y se establecieron en zonas periféricas, bien de colonización campesina donde bullían conflictos agrarios (FARC-EP) ${ }^{8}$, o en aquellas regiones de explotación petrolífera, escenario de luchas obreras $(\mathrm{ELN})^{9}$. Desde tales puntos se proyectaron hacia las zonas con prosperidad económica (como la explotación de los recursos naturales, el auge del narcotráfico o el contrabando en las fronteras). Por su parte, las autodefensas, constituyéndose en la reacción contrainsurgente de varios sectores pudientes ${ }^{10}$, se instalaron en las cabeceras municipales, integradas en la economía nacional o donde existían poderes regionales relativamente autónomos ${ }^{11}$.

Este arraigo territorial de los combatientes dio al conflicto un rasgo marginal y periférico, que junto con la dualidad estructural del país ${ }^{12}$, evitó durante varias décadas que la confrontación tuviera un impacto significativo en aspectos centrales de la vida nacional. Sin embargo, este carácter secundario se transformó a finales de los noventa, cuando los enfrentamientos irrumpieron en regiones con actividades sensibles para la política y la economía del país: zonas de cultivos ilícitos ${ }^{13}$, escenarios de infraestructura eléctrica, petrolera y de gas $^{14}$; así como las fronteras de Panamá, Ecuador y Venezuela ${ }^{15}$. Estas nuevas

${ }^{8}$ Fuerzas Armadas Revolucionarias de Colombia, Ejército del Pueblo (FARC-EP)

${ }^{9}$ Ejército de Liberación Nacional (ELN)

${ }^{10}$ Como narcotraficantes, comerciantes, mineros, ganaderos, terratenientes y militares.

${ }^{11}$ Estrada, F. (2006): «Estado Mínimo, Agencias de Protección y Control Territorial». Análisis Político, 56, pp. 115-131.

12 El desarrollo histórico nacional ha dado lugar a la coexistencia de dos realidades, un país urbano, moderno, influyente y dinámico; de otro menos poblado, más campesino, menos integrado al mercado, con menor poder político y, a menudo, discriminado y explotado por el primero. Programa de las Naciones Unidas para el Desarrollo (PNUD) (2003): El conflicto, callejón con salida..., p. 21.

${ }^{13}$ Uno de los mecanismos de encuentro fue la irrupción de los cultivos ilícitos en bastiones guerrilleros, así como la movilización de los aparatos armados hacia los lugares de procesamiento y comercialización de productos de coca. Circunstancia que permitió la retroalimentación de ambos fenómenos. Programa de las Naciones Unidas para el Desarrollo (PNUD) (2003): El conflicto, callejón con salida..., pp. 87 y 88.

${ }^{14}$ Por su carácter vital, de provisión nacional y de exportación, estas infraestructuras terminaron convirtiéndose en blanco de atentados u objeto de lucha entre guerrillas y autodefensas para hacerse con el manejo de las regalías. Asimismo, para la insurgencia fue un aspecto táctico importante, para obligar al Estado a dirigir sus esfuerzos a tales puntos, descuidando, al mismo tiempo, otros territorios.

${ }^{15}$ La ubicación fronteriza ofrecía ventajas no sólo como refugio y corredores de desplazamiento, sino también para el desarrollo de actividades ilícitas como el narcotráfico, la compraventa de armas o el contrabando de gasolina. Costa Vaz, A. (2005): «El conflicto colombiano: una perspectiva global», en M. Ardilla, D. Cardona y S. Ramírez (eds.): Colombia y su política exterior en el siglo XXI. Bogotá, Friederich Ebert Stiftung, CEREC, pp. 10 y ss. 
circunstancias provocaron un cambio radical, en los planteamientos tradicionales del Gobierno; pues, erigió la confrontación como la principal prioridad a solucionar y buscó la ayuda internacional, para realizar dicho objetivo.

\section{La propuesta militar de Estados Unidos}

La situación colombiana era observada por Estados Unidos con preocupación, por la repercusión que esta tenía en sus intereses: el repunte del narcotráfico, la inestabilidad andina y la creciente debilidad estatal para enfrentar tales problemas. Siguiendo su preferencia por los medios de fuerza, Washington propuso a Colombia el fortalecimiento militar de su Estado, con el que pudiera derrotar a los grupos armados y recuperar el control de las extensiones donde proliferaban los cultivos ilícitos protegidos por aquéllos. Dicha asistencia se canalizó en iniciativas como el Plan Colombia, y sus consiguientes desarrollos, que operaron en los departamentos de Putumayo y Caquetá, al sur del país ${ }^{16}$.

Esta propuesta favoreció una importante modernización del Ejército colombiano, que a través de diferentes operaciones militares consiguió el repliegue de la guerrilla. Dichas acciones se inscribieron en la Política de Seguridad Democrática, en el marco de la cual, el Gobierno también implementó otras propuesta sociales complementarias, aunque con un perfil menos ambicioso $^{17}$. Si bien este énfasis responde a la necesidad apremiante de la seguri-

${ }^{16}$ En efecto, la primera iniciativa formulada por Estados Unidos fue el Plan Colombia (al que asignó una partida de US\$ 1.300 millones de dólares aprobada en 2000), que preveía la creación de una unidad antidroga del Ejército colombiano, que además de labores de fumigación, debilitaría la custodia que ejercía la guerrilla de las FARC en los departamentos mencionados. Esta vertiente contra-insurgente se reforzó, con dotaciones adicionales inspiradas en la lucha antiterrorista: por una parte, la partida para la protección de infraestructura petrolera de gas y redes eléctricas (US\$ 98 millones de dólares en 2003); y por otra, la puesta en marcha del Plan Patriota (evolución del Plan Colombia con una inversión inicial de US\$ 110 millones de dólares en 2003 y que en 2006 alcanzó la cifra de US\$3.700 millones). El aspecto regional andino fue contemplado con asignaciones específicas del Plan Colombia y en lo que se denominó como Iniciativa Regional Andina. Ramírez, S. (2001): «La internacionalización del conflicto y la paz en Colombia», en Instituto de Estudios Políticos y Relaciones Internacionales (IEPRI): El Plan Colombia y la Internacionalización del Conflicto. Bogotá, Planeta, Universidad Nacional de Colombia, p. 89; Ramírez, S. (2004): Intervención en conflictos internos: el caso colombiano (1994-2003). Bogotá, Universidad Nacional de Colombia, p. 259.

${ }_{17}$ Así lo argumenta González al señalar que «la estrategia y concepción misma del control territorial en el diseño de las políticas públicas presenta un desfase a favor de los aspectos puramente militares y policiales». Dicha afirmación se sustenta en la sustancial diferencia de recursos invertidos por el Ministerio de Defensa en las acciones armadas y los destinados al Programa de la Presidencia de la República, Centro de Coordinación de Acción Integral 
dad, no es suficiente para alcanzar el objetivo gubernamental de recuperar la presencia y el control estatal a lo largo de la geografía nacional ${ }^{18}$. Al respecto, deben tomarse en consideración, los aspectos sociales e institucionales de las regiones que propician la violencia. El tratamiento de los mismos resulta fundamental, para instaurar la gobernabilidad local, así como para establecer las bases que permitan construir una paz duradera.

\section{LAS INICIATIVAS DE PAZ Y EL APOYO DE LA UNIÓN EUROPEA}

Una respuesta en el sentido social e institucional mencionado se ha generado desde los propios territorios; pues, ante el recrudecimiento de la violencia en distintas localidades y la insuficiencia de las políticas centrales, los habitantes han decidido organizarse y emprender sus propias iniciativas. Estas actuaciones han partido del liderazgo de una o varias instituciones representativas de la sociedad, que convocan a la ciudadanía para encontrar nuevas formas de organización y encarar así, las dificultades impuestas por la confrontación a través del diálogo ${ }^{19}$. En sus diferentes formas, han procurado estructurar y concienciar a la población en torno a la resistencia civil y a las negociaciones con los frentes armados. De esta manera, se han podido persuadir ataques, alcanzar acuerdos humanitarios, retornar poblaciones o recuperar vías tomadas ${ }^{20}$. Asimismo, también se han promovido actividades de desarrollo, con las cuales mitigar algunos de los problemas estructurales que alimentan el conflicto, como la pobreza, la inadecuada distribución de la riqueza o la débil presencia del Estado en dichas zonas ${ }^{21}$.

(CCAI), encargada de desarrollar acciones de tipo económico y social entre distintas agencias. González Pérez, Á. C. (2007): "Control territorial y gobernabilidad en zonas afectadas por la presencia de grupos armados ilegales en Colombia”, en: Conferencia de Defensa y Seguridad. Enfrentando desafios transnacionales. Aproximación a la cooperación regional de defensa y seguridad. Centro de Estudios Hemisféricos de Defensa (CHDS), Lima, Perú, p.13. Disponible en: http://www.ndu. edu/chds/SRC-peru07/SRC_PAPERS/TRACK\%201/Gonzalez.pdf (Fecha de consulta: 15/05/2012).

18 González Pérez, Á. C. (2007): "Control territorial y gobernabilidad en zonas afectadas por la presencia de grupos armados ilegales en Colombia", pp. 9 y 10.

19 Programa de las Naciones Unidas para el Desarrollo (PNUD) (2003): El conflicto, callejón con salida..., p. 341. Una muestra de dicha labor son las comunidades y territorios de paz, las asambleas constituyentes y los Programas de Desarrollo y Paz.

20 Programa de las Naciones Unidas para el Desarrollo (PNUD) (2003): El conflicto, callejón con salida..., p. 337.

${ }^{21}$ García, A. y Sarmiento, A. (2002): Programas Regionales de Desarrollo y Paz: casos de capital social y desarrollo institucional. Bogotá, Fundación Ideas para la Paz, p. 6. Disponible en:http://www. ideaspaz.org/portal/images/programas_regionales_desarrollo_paz.pdf (Fecha de consulta: 15/11/2012). 
Esta dinámica participativa y dialogante comienza a generar condiciones de pacificación en tres ámbitos estratégicos: i) la reestructuración del tejido social; ii) el fortalecimiento de las relaciones en el interior de la comunidad; y iii) el establecimiento de un nuevo vínculo entre ésta y la Administración local. El reforzamiento en dichos campos, permite a estas iniciativas operar en aquellas estructuras socio-políticas de los territorios que propician la instalación y el arraigo de los grupos armados ilegales en las regiones.

\section{Los Laboratorios de Paz: la experiencia del Magdalena Medio}

El apoyo de la Unión Europea a la paz de Colombia se desplegó mediante los denominados Laboratorios de Paz, con los cuales la UE buscó «fortalecer y resaltar estas formas y experiencias de resistencia civil frente al conflicto armado, que promueven el diálogo por la paz e indican caminos promisorios para atacar sus causas socioeconómicas» 22 . Por su planteamiento y trayectoria, el respaldo europeo se dirigió hacia los Programas de Desarrollo y Paz (PDP); iniciativas surgidas de la alianza entre comunidades y sectores sociales específicos, que con cierto respaldo estatal, han ejecutado proyectos integrales de desarrollo productivo, fortalecimiento institucional y construcción de una Cultura de $\mathrm{Paz}^{23}$. Según este enfoque, los Laboratorios se constituyen en programas de cooperación internacional, con los que se financian propuestas formuladas y realizadas por la población, en coordinación con las organizaciones sociales y la Administración Pública ${ }^{24}$.

${ }^{22}$ En ese sentido, la UE traza tres objetivos a alcanzar en las regiones donde se despliegan dichos programas: i) edificar zonas de coexistencia pacífica para los habitantes, mediante el fortalecimiento de las instituciones locales y el apoyo a los actores civiles involucrados en la promoción de la paz; ii) fomentar el desarrollo económico y local, incluyendo en lo posible el desarrollo alternativo; y iii) apoyar, sobre el terreno, la implementación de acuerdos específicos firmados por las partes en conflicto. Delegación de la Unión Europea para Colombia y Ecuador (2005): La Unión Europea y Colombia, p. 20. Disponible en: http: //www.delcol.cec.eu. int/es/novedades/Separata\%20de\%20cooperación.pdf (Fecha de consulta: 15/11/2012).

${ }^{23}$ Herrera Rivera, L. Á. (2007): «Los Programas de Desarrollo y Paz: la construcción de un sujeto histórico-social y la participación social», noviembre. Disponible en: http://www.institutgouvernance.org/fr/analyse/fiche-analyse-341.html (Fecha de consulta: 15/11/2012).

${ }^{24}$ Desde esta perspectiva, la ayuda de la UE es percibida como «un mero instrumento de apoyo a los procesos y dinámicas, que ya se están dando en el seno de la sociedad civil colombiana». Rudqvist, A. y Van Sluys, F. (2005c): Evaluación Medio Tiempo Laboratorio de Paz en el Magdalena Medio. Contrato Marco AMS/451- Lote No 8. Carta de Contrato N ${ }^{o}$ 2004/86726 con ECO, Febrero, p. 3. Disponible en http: //www.delcol.cec.eu.int/es/index.htm (Fecha de consulta: 15/11/2012). 
FIGURA 1

LOCALIZACIÓN DE LOS LABORATORIOS DE PAZ

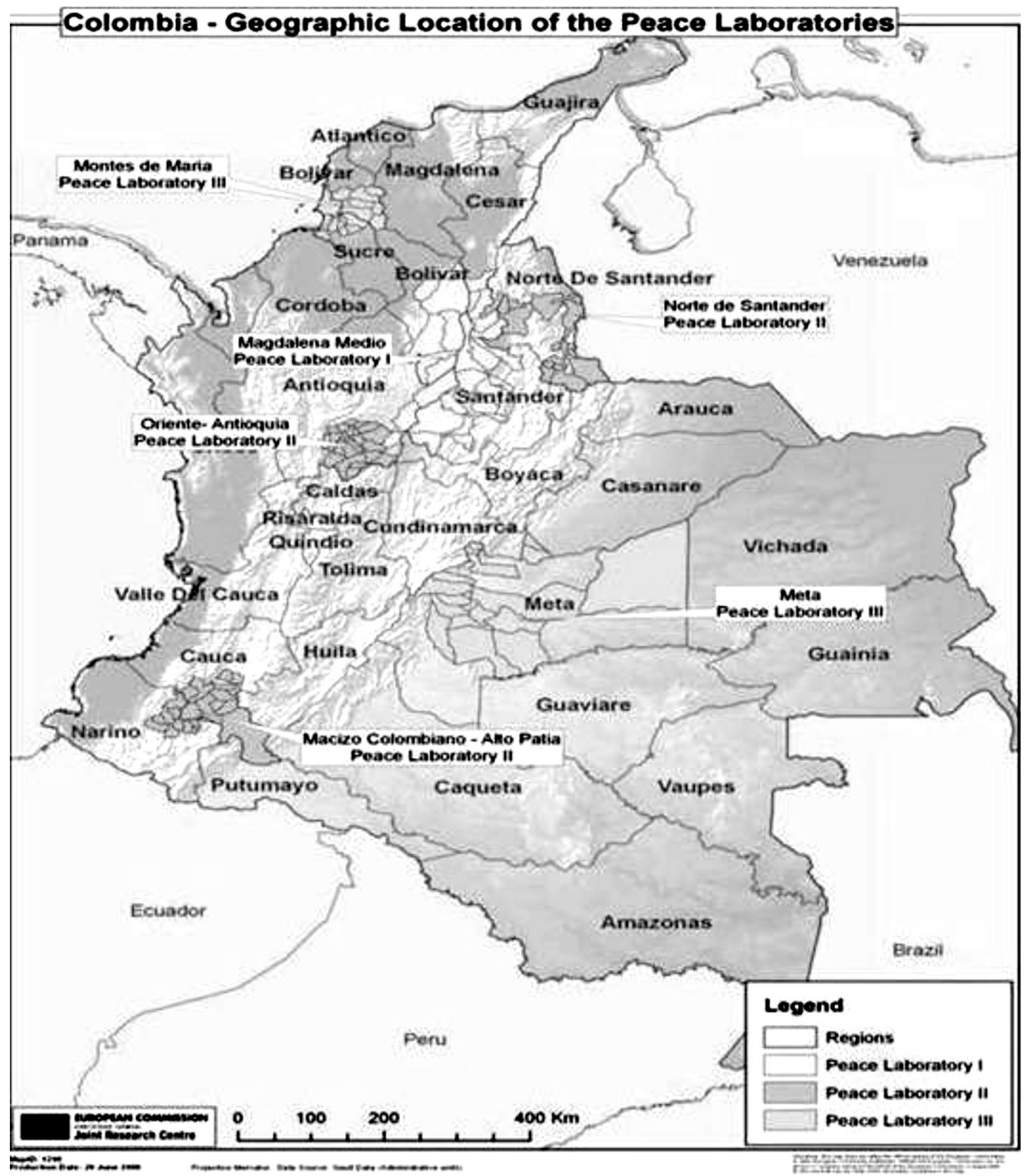

Fuente: Fundación Red Desarrollo y Paz de los Montes de María. Disponible en: http://www.fmontesdemaria.org/index.php?option=com_content $\&$ view=article\&id=139\%3Alaboratorio-paz-iii\&catid=80\&lang=es (Fecha de consulta: 11/03/2013). 
Desde la formalización de su compromiso, la UE ha ejecutado tres Laboratorios de Paz en diferentes regiones colombianas (figura 1) ${ }^{25}$. El primer programa se desarrolló en el denominado Magdalena Medio, al noreste del país (figura 2); que surgió como respaldo al proceso ya iniciado por el PDPMM ${ }^{26}$, con el objetivo de fortalecer su labor en la convivencia ciudadana y el diálogo de paz; a través de la defensa de los derechos humanos y el impulso del desarrollo sostenible ${ }^{27}$.

En su ejecución, el Laboratorio de Paz del Magdalena Medio (LPMM) dio continuidad al protagonismo central de la población, como actor idóneo para construir la paz en su territorio. Este énfasis hizo que el LPMM considerara a la sociedad civil no sólo como su objetivo, sino que además la señaló como el vehículo mediante el cual, llevaría a cabo su ejecución. Dado este enfoque, el programa produciría resultados tempranamente desde la puesta en marcha de sus actividades. Dicha tarea se lograría mediante la articulación de procesos

${ }^{25}$ Los Laboratorios puestos en marcha hasta ahora, y las respectivas iniciativas locales a las que se adhirieron fueron: I Laboratorio de Paz (2002-2009) desarrollado en el Magdalena Medio (PDPMM); II Laboratorio de Paz (2003-2009) desarrollado en el Norte de Santander (PDP NOR); Occidente Antioqueño (PRODEPAZ); Macizo colombiano (CRIC); Alto Patía (ASOPATÍA). El III Laboratorio de Paz (2006-2011) se ejecutó en el departamento del Meta (CORDEPAZ) y la región de los Montes de María (FRDPMMA). Los tres programas suman una financiación total de $€ 113.870 .000$ millones de euros, donde el Gobierno colombiano realizó aportaciones minoritarias.

${ }^{26}$ El Programa de Desarrollo y Paz del Magdalena Medio (PDPMM) surgió en 1995 a partir de la alianza de actores como: la Diócesis de Barrancabermeja, la Unión Sindical Obrera (USO), la Empresa Colombiana de Petróleos (ECOPETROL) y el Centro de Investigación y Educación Popular de Colombia (CINEP), con el fin de buscar una salida a la situación de violencia y pobreza de la región. El Programa es dirigido por la Corporación Desarrollo y Paz del Magdalena Medio (CDPMM) conformada por la Diócesis de Barrancabermeja y el CINEP. Corporación Desarrollo y Paz del Magdalena Medio-CDPMM (sin fecha): Programa Desarrollo y Paz del Magdalena Medio: Informe de la primera fase del Laboratorio de Paz, p. 13. Disponible en: http://www.pdpmm.org.co/docs/pdf/informeagosto.pdf (Fecha de consulta: 15/11/2012); García, A. y Sarmiento, A. (2002): Programas Regionales de Desarrollo y Paz: casos de capital social y desarrollo institucional, p. 23.

27 Así se puede concluir de lo señalado en el Convenio de Financiación y el Plan Operativo Global del Laboratorio de Paz del Magdalena Medio. Rudqvist, A. y Van Sluys, F. (2005): Evaluación Medio Tiempo Laboratorio de Paz en el Magdalena Medio. Anexo 3. Términos de referencia de la misión, p. 2. Disponible en: http://www.delcol.cec.eu.int/es/index.htm (Fecha de consulta: 15/11/2012); Rudqvist, A. y Van Sluys, F. (2005): Evaluación Medio Tiempo Laboratorio de Paz en el Magdalena Medio. Anexo 2. Plan Operativo Global 2002-2005: marco lógico, cronograma general y descripción de actividades, p. 5. Disponible en http://www.kus.uu.se/pdf/publications/ Colombia/Anexo2.pdf 
FIGURA 2

CARACTERÍSTICAS GENERALES DE LA REGIÓN DEL MAGDALENA MEDIO

Se sitúa al noreste de Colombia, es atravesada de sur a norte por el Río Magdalena en un trayecto de 300 kilómetros y determina un espacio de 30 mil kilómetros cuadrados. A pesar de conformar una región geográfica, los municipios que la integran dependen política y administrativamente de cuatro departamentos diferentes: Santander, Bolívar, Cesar y Antioquia. La acción del PDPMM, al que se incorpora el Laboratorio, cubre un conjunto de 30 municipios predominantemente rurales, a excepción de los dos epicentros urbanos de la región (Barrancabermeja y Aguachica) y cuenta con una población objetivo de 450 mil habitantes. La región tiene una importancia geoestratégica nacional, por su localización céntrica y por sus recursos naturales. Es el punto de confluencia entre el interior del país y la costa atlántica; y, entre la región pacífica y Venezuela. De ahí que dicha zona sea objeto de importantes proyectos de infraestructura ${ }^{1}$. Por otra parte, dada la disponibilidad de sus recursos, el Magdalena Medio se ha establecido históricamente como una economía de enclave exportador de materias primas. Durante el siglo XIX, la quina, el tabaco y la madera fueron productos objeto de explotación; y, en la actualidad lo son el petróleo y algunos productos agrícolas como la palma de aceite, la soja y el algodón. Sin embargo, como consecuencia del modelo económico de extracción, el Magdalena Medio experimenta una paradoja: es una región que explota sus diversos recursos, pero todos sus municipios, a excepción de Barrancabermeja, poseen dramáticos índices de pobreza².

Notas:

(1) Infraestructuras como las troncales del Magdalena Medio en territorio santandereano y antioqueño; la transversal Cisneros-Cimitarra-Vélez y un eventual canal seco entre Venezuela y el Pacífico que atravesaría el Río Magdalena en la Región. Finalmente las mejoras en navegabilidad del Río Magdalena y del ferrocarril. Programa de Desarrollo y Paz del Magdalena Medio. Tomado de la página web del programa: http://www.pdpmm.org.co/

(2) Importantes casos de pobreza en algunos municipios cuya población se encuentra con sus Necesidades Básicas Insatisfechas son: Morales 91.8\%, Simití 87.1\%, San Pablo 86.3\% y Wilches 76.3\%.

Fuente: elaboración propia a partir de información obtenida de la página web del Programa de Desarrollo y de Paz del Magdalena Medio. Disponible en: Programa de Desarrollo y Paz del Magdalena Medio. Tomado de la página web del programa: http://www.pdpmm.org.co/ (Fecha de consulta: 11/03/2013).

participativos, en los cuales se formularan y ejecutaran proyectos de desarrollo y de paz en tres áreas centrales: i) la esfera productiva, ii) la convivencia ciudadana y iii) la presencia institucional ${ }^{28}$. Estas propuestas buscaron impactar la dinámica regional, que propicia la presencia y el arraigo de los grupos armados en la región.

\footnotetext{
${ }^{28}$ Ibíd.
} 


\section{La sociedad civil partícipe del desarrollo del LPMM}

La actuación de la población en el desarrollo del LPMM comenzó en la convocatoria, a todas las organizaciones de la región, para que elaboraran propuestas a ser financiadas con los recursos europeos ${ }^{29}$. Asimismo, se acordó la vinculación de diversos grupos y asociaciones de las localidades, para la realización de los proyectos elegidos ${ }^{30}$. Si bien el proceso no estuvo exento de dificultades $^{31}$, dicha invitación arrojó una amplia participación, que trajo varios resultados positivos ${ }^{32}$.

Esta colaboración por parte de diversos sectores es, según Albuquerque, una condición necesaria para el desarrollo exitoso de las iniciativas locales: «Cuanto mayor sea el número de implicados, más prominente es el esfuerzo en concretar voluntades, animar diálogos, diseñar agendas públicas e institucionales, construir redes sociales, así como asumir y compartir responsabilidades $[\ldots] »^{33}$. Este aspecto resultó fundamental para la construcción de la paz

${ }^{29}$ En ese sentido se llevó a cabo un esfuerzo de planeación participativa que congregó a más de dos mil pobladores en los diferentes eventos realizados con ese fin. Se crearon comités municipales ad hoc, con representantes de las organizaciones sociales, de los núcleos de pobladores y de la administración municipal en cada uno de los 13 municipios que conformaron la primera fase del Laboratorio de Paz. Asimismo, se creó un comité encargado de la aprobación de los proyectos regionales y estratégicos. Corporación Desarrollo y Paz del Magdalena MedioCDPMM (2004b): Plan Operativo Anual (POA) Resumen Ejecutivo, p. 6. Disponible en: http://www.pdpmm.org.co/labpaz/poa (Fecha de consulta: 15/11/2012).

${ }^{30}$ De esta manera, se buscó que las organizaciones adquirieran conocimiento y acumularan experiencia. Fue característico el caso de los proyectos económicos ejecutados por diferentes asociaciones y gremios, cuyas alianzas con otras instituciones sociales sirvió para su asignación como operadores. Corporación Desarrollo y Paz del Magdalena Medio-CDPMM (sin fecha): Programa Desarrollo y Paz del Magdalena Medio: Informe de la primera fase del Laboratorio de Paz, p. 13. Disponible en: http://www.pdpmm.org.co/docs/pdf/informeagosto.pdf (Fecha de consulta: 15/11/2012).

${ }^{31}$ Dificultades como el desorden y la poca madurez de las iniciativas, así como su énfasis en los componentes económicos, dadas las necesidades no satisfechas por el Estado y su abandono histórico. íbidem.

32 i) dio legitimidad social al proceso puesto en marcha; ii) otorgó al Laboratorio un carácter transparente e incluyente; iii) estableció contactos novedosos, con actores en otrora lejanos y iv) contribuyó al fortalecimiento de muchos grupos de la población, ante la intimidación impuesta por los aparatos armados ilegales. Corporación Desarrollo y Paz del Magdalena MedioCDPMM (sin fecha): Programa Desarrollo y Paz del Magdalena Medio: Informe de la primera fase del Laboratorio de Paz, p. 22-23.

33 Albuquerque, F. (2004): «Desarrollo económico local y descentralización en América Latina». Revista de la CEPAL, 82, abril, pp. 157-171 [p. 169]. Disponible en: http://digital.csic. es/bitstream/10261/10544/1/lcg2220e-Alburquerque.pdf (Fecha de consulta: 15/11/2012). 
en la región, como lo apunta la Corporación responsable Corporación Desarrollo y Paz del Magdalena Medio (CDPMM): «[...] el aporte más relevante de este proceso incluyente fue la conciliación de distintas posiciones. Cada proyecto fue entendido como una mesa de negociación y un espacio para solucionar en el diálogo la diferencia de intereses. Este es un ejemplo de la lucha de los protagonistas, para alcanzar la convivencia ${ }^{34}$. De manera que el LPMM se ubicó en la senda de sus objetivos, desde su puesta en marcha.

\section{La sociedad civil como objetivo del desarrollo del LPMM}

El desarrollo del LPMM se estructuró sobre cuatro componentes: i) Cultura de Paz-Derechos Humanos; ii) Actividades económicas; iii) Infraestructura y iv) Fortalecimiento Institucional, en torno a los cuales se formularon los distintos proyectos ${ }^{35}$. Todas las iniciativas seleccionadas se desplegaron prioritariamente en 12 Espacios Humanitarios, definidos en las zonas más golpeadas por la confrontación y en donde su nivel de inseguridad no impidiera la ejecución del Laboratorio ${ }^{36}$. El programa operó de manera escalonada, con el objetivo de impactar en dos ámbitos estratégicos filtrados por el conflicto: las relaciones entre la Comunidad y el vínculo de aquélla con el Estado. En ese sentido, la ejecución del LPMM partió en la población más sacudida por la violencia, continuó en el fortalecimiento de asociaciones y concluyó en una comunicación novedosa de la ciudadanía con la Administración Local37 (figura 3).

34 Corporación Desarrollo y Paz del Magdalena Medio-CDPMM (sin fecha): Programa Desarrollo y Paz del Magdalena Medio: Informe de la primera fase del Laboratorio de Paz, p. 5.

35 La convocatoria abierta por el LPMM evidenció la escasa capacitación de la comunidad para formular proyectos integrales, que fueran más allá de las tradicionales solicitudes de infraestructura y proyectos productivos puntuales. En consecuencia, el énfasis de las propuestas fue para dichos componentes económicos (en un $80 \%$ ) en detrimento de las demás líneas estratégicas. Esta situación presionó una readaptación de las propuestas hacia un énfasis en la paz. Corporación Desarrollo y Paz del Magdalena Medio-CDPMM (2004b): Plan Operativo Anual (POA) Resumen Ejecutivo, p. 3.

${ }^{36}$ En los mismos se llevó a cabo un plan de ayuda humanitaria y otro en materia de paz y desarrollo, replicando las experiencias positivas en otras localidades de la región, en la segunda fase del programa.

${ }^{37}$ La visión que sostiene el Laboratorio de Paz es básicamente la creación de nuevas relaciones humanas a través de la perspectiva de la no violencia, el diálogo y la resistencia civil. Pax Christi International (2006): «Seeking Peace in Colombia». International Report, Brussels, p. 48. 
FIGURA 3

POBLACIONES DEL LABORATORIO DE PAZ DEL MAGDALENA MEDIO

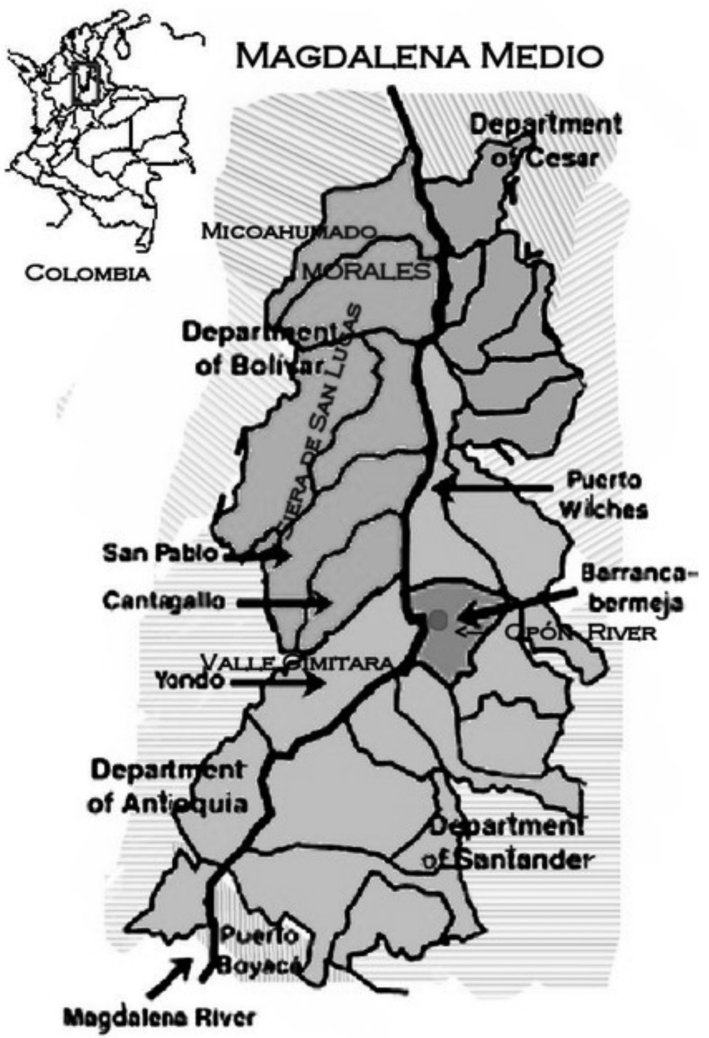

Fuente: Christian Peacemaker Teams (CPT). Disponible en: http://www.cpt.org/work/colombia (Fecha de consulta: 11/03/2013).

a. Las relaciones en el interior de la Comunidad

Este planteamiento supuso dos tipos de actuaciones: una, en la base de la población y otra, en su aspecto organizativo. En ese sentido, el componente de Derechos Humanos buscó instaurar una Cultura de Paz, para facilitar el acercamiento entre los habitantes, restituir su confianza y recuperar su sentido de identidad y de pertenencia. Al respecto, se impulsaron varios procesos que tuvieron como propósito la eliminación del concepto amigo-enemigo, la implantación de valores pacíficos y la promoción de creencias y actitudes al- 
ternativas a la violencia ${ }^{38}$. Por otra parte, el Laboratorio promovió el reforzamiento y la creación de nuevas asociaciones, donde se evidenciara la heterogeneidad de sectores sociales y la diversidad de sus intereses. Dichas estructuras fueron capacitadas en materia de derechos humanos y contaron con espacios de concertación y debate, que permitieron a los habitantes, plantear los retos que enfrenta su territorio (especialmente aquellos relacionados con el impacto de la confrontación) y sus posibles soluciones ${ }^{39}$.

La puesta en marcha de estos procesos promovió cambios en diferentes ámbitos comunitarios, como por ejemplo: el restablecimiento del tejido social, el nacimiento de un nuevo imaginario colectivo y la identificación de prioridades comunes. A su vez, dichos elementos contribuyeron a que un número mayor de pobladores, adquirieran una perspectiva civil y dialogante, frente a cuestiones tan álgidas como las tensiones sociales, cuya irresolución termina atrayendo a los grupos armados ${ }^{40}$. Cabe señalar que, como complemento de la consecución de tales logros, el LPMM también desarrolló iniciativas económicas con dos propósitos: atacar factores como el desempleo y la pobreza, que tienden a presionar a los habitantes (sobre todo los más jóvenes) a adherirse a la lucha armada; así como ofrecer alternativas a quienes se dedican al cultivo

${ }^{38}$ En ese sentido el LPMM impulsó contenidos de paz en programas radiales, así como actividades culturales y diferentes propuestas de educación. Corporación Desarrollo y Paz del Magdalena Medio-CDPMM (sin fecha): Programa Desarrollo y Paz del Magdalena Medio: Informe de la primera fase del Laboratorio de Paz, pp. 18 y 20.

39 Este trabajo fue especialmente destacado en organizaciones de mujeres y jóvenes, productores agrícolas, comerciantes y educadores. El Laboratorio buscó que la sociedad asimilara los derechos humanos en sus principios, perspectivas y herramientas para su exigibilidad. Concienciada y capacitada, se esperaba aumentar el potencial de la población para promover y crear propuestas que le permitieran obtener la garantía de sus derechos. Corporación Desarrollo y Paz del Magdalena Medio-CDPMM (sin fecha): Programa Desarrollo y Paz del Magdalena Medio: Informe de la primera fase del Laboratorio de Paz, p. 13. Como ejemplo de estos procesos participativos son las mesas de diálogo y «conversatorios» donde se propuso discutir las causas y consecuencias del conflicto, los cultivos ilícitos o la distribución de la tierra. Corporación Corporación Desarrollo y Paz del Magdalena Medio-CDPMM (2004c): Plan Operativo Anual (POA) Intervención, p. 11 Disponible en: http://www.pdpmm.org.co/labpaz/poa (Fecha de consulta: 15/11/2012).

${ }^{40}$ Dichas actividades tuvieron especial impacto en las relaciones de ciertas actividades productivas, cuya trayectoria histórica ha estado marcada por tensiones sociales y laborales, como fue el caso de la palma africana y la explotación de algunos recursos naturales. Corporación Desarrollo y Paz del Magdalena Medio-CDPMM (sin fecha): Programa Desarrollo y Paz del Magdalena Medio: Informe de la primera fase del Laboratorio de Paz, pp. 15-16; Corporación Desarrollo y Paz del Magdalena Medio-CDPMM (2004c): Intervención, pp. 27-35. 
de coca o el mercado negro de gasolina, negocios que han sustentado las finanzas del conflicto ${ }^{41}$.

\section{b. El vínculo entre Comunidad y Administración Local}

La población organizada, con capacidad participativa y apropiada de las dificultades de su territorio requiere de alianzas con la Administración Local, para formular soluciones conjuntas. Dicha necesidad es abordada por el componente del Fortalecimiento Institucional, que previó crear condiciones y capacidades en la sociedad, que le permitieran participar en el diseño de las políticas territoriales, así como ejercer el control sobre la gestión de las mismas ${ }^{42}$. Esta acción se apoyó en los demás componentes, que propiciaron los ámbitos donde Comunidad y Estado pudieran cooperar ${ }^{43}$. El éxito de estos espacios posibilitó abordar uno de los aspectos que más impulsan el conflicto en las regiones: la interferencia de los grupos armados entre la ciudadanía y las instituciones estatales, en ámbitos tan relevantes como la protesta social y el desvío de los recursos públicos, comúnmente conocida como «clientelismo armado».

\section{CONCLUSIÓN}

El examen de la confrontación colombiana, en su perspectiva regional, permite constatar la manera en que el territorio ha jugado un papel esencial en varios aspectos relacionados tanto con su desarrollo, como con la búsqueda de soluciones, que han conectado el ámbito local con la esfera internacional.

${ }^{41}$ En el área rural destacó el proyecto de la «finca campesina»y en el ámbito urbano, las «microempresas». Corporación Desarrollo y Paz del Magdalena Medio-CDPMM (sin fecha): Programa Desarrollo y Paz del Magdalena Medio: Informe de la primera fase del Laboratorio de Paz, pp. 13 y 19.

42 Ante dichos objetivos, el Laboratorio desarrolló estrategias de capacitación a funcionarios y organizaciones sobre el diseño y aplicación de indicadores de seguimiento, evaluación, planeación participativa y liderazgo en varios municipios. Corporación Desarrollo y Paz del Magdalena Medio-CDPMM (sin fecha): Programa Desarrollo y Paz del Magdalena Medio: Informe de la primera fase del Laboratorio de Paz, p. 19.

${ }^{43}$ Ejemplo de este planteamiento, fueron las inversiones en obras de infraestructura, la explotación sostenible de recursos naturales o la inclusión de los derechos humanos en los planes de desarrollo. Corporación Desarrollo y Paz del Magdalena Medio-CDPMM (sin fecha): Programa Desarrollo y Paz del Magdalena Medio: Informe de la primera fase del Laboratorio de Paz, $\mathrm{p}$. 12 y Corporación Desarrollo y Paz del Magdalena Medio-CDPMM (2004c): Intervención, p. 13. 
El dinamismo del conflicto armado se sustenta en las diferentes ventajas que brindan los territorios a los combatientes, siendo la lucha por el control de las localidades uno de sus objetivos fundamentales y la expresión más viva de la confrontación. De ahí que resulte conveniente actuar sobre las condiciones que, desde las mismas regiones, proporcionan beneficios a los actores armados.

Las diferentes propuestas internacionales de paz respondieron a esta dimensión local, aunque el énfasis y el enfoque de las mismas fueron divergentes. Estados Unidos formuló una actuación de fuerza «desde arriba», buscando impactar los factores económicos como el narcotráfico; y de esta manera, alcanzar la seguridad. Por su parte, la Unión Europea, defensora de la solución política del conflicto, fue la valedora de la alternativa social, apoyando a las poblaciones que en sus territorios, buscan cerrar los espacios donde la violencia se ha infiltrado. Dichos principios civiles fueron fortalecidos en la propuesta del primer Laboratorio de Paz del Magdalena Medio, a través de los cuatro componentes previstos en su despliegue. Éstos planteaban una acción directa y complementaria sobre las relaciones privadas y público-privadas de la región, a través de una intervención escalonada, que partió de los sectores más vulnerables, pasó por el fortalecimiento organizacional, hasta llegar a una nueva vinculación entre la Comunidad y la institucionalidad local.

Debe advertirse que esta diferencia de enfoques en la ayuda exterior pudo haberse subsanado desde la política colombiana, reconociendo la necesaria complementariedad de ambos medios y de su pertinente aplicación. Sin embargo, la prioridad del Gobierno se ha centrado en atacar los factores económicos y tácticos, mediante el uso de la fuerza. Esta decisión deja en un segundo plano la base social e institucional, que ha permitido a los grupos armados usufructuar los demás beneficios territoriales.

Juliana Rivera UNED 